\title{
Associação de leishmaniose visceral e hepatite B de curso fulminante: relato de um caso
}

\author{
Visceral leishmaniasis and B fulminant hepatitis \\ association: case report
}

Pérsio Godoy ${ }^{1}$ e Paulo Guilherme de Oliveira Salles ${ }^{1}$

\begin{abstract}
Resumo É relatado o caso de paciente de 20 anos com hepatoesplenomegalia, febre e grave insuficiência hepática. Estudos histopatológicos e imunohistoquímicos de fragmentos hepáticos obtidos em necropsia permitiram o diagnóstico de leishmaniose visceral e hepatite fulminante pelo vírus $B$. Os autores apontam possível influência da resposta imunitária relacionada com a leishmaniose visceral no desenvolvimento de grave lesão hepática pelo vírus $B$ da hepatite.
\end{abstract}

Palavras-chaves: Leishmaniose. Hepatite. Co-infecção. Imunologia. Patologia.

Abstract The case of a 20-year-old man with hepatoesplenomegaly, fever and severe hepatic insufficiency is reported. Histopathological and immunohistochemical studies of tissue specimens obtained at autopsy led to diagnosis of visceral leishmaniasis and fulminant hepatitis $B$. The authors pointed out a possible influence of immunological response related with visceral leishmaniasis in development of severe hepatic involvement by hepatitis $B$ virus

Key-words: Leishmaniasis. Hepatitis. Coinfection. Immunology. Pathology.

\begin{abstract}
A leishmaniose visceral (LV) e a hepatite pelo vírus B são freqüentes no Brasil e apresentam quadro clínico e anátomo-patológico variável, por vezes grave. Separadamente são comuns, porém associadas não têm sido relatadas, exceto em caso isolado com a hepatite viral em sua forma crônica e na vigência de tratamento com interferon ${ }^{10}$.
\end{abstract}

A LV é capaz de determinar imunossupressão antígeno-específica peculiar que possibilitaria a superinfecção e o comprometimento da resposta imunitária a outras doenças, seja através de imunocomplexos ou, sobretudo, por interferência na resposta celular, inibindo a proliferação linfocitária e a produção de determinadas linfocinas, especialmente do interferon- $\gamma$ (INF- $\gamma$ ) e das interleucinas 2 e 12 (IL-2 e IL12), além do aumento expressivo na síntese do fator de necrose tumoral alfa (TNF- $\alpha)^{45131518}$. Os mecanismos envolvidos são mal definidos e distintos de outras doenças infecciosas que comprometem a função linfocitária, inclusive a AIDS - a LV em áreas endêmicas vem constituindo infecção oportunística, facilitando a infecção pelo HIV e acelerando seu curso ${ }^{131617}$.

A lesão hepatocitária na hepatite pelo vírus $B$ envolve a persistência da infecção que origina antígenos para reconhecimento e necrose hepatocitária, via ação citotóxica dos linfócitos T, produção de interferon gama

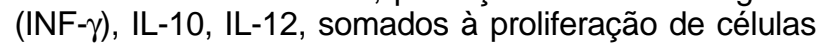
mononucleares, elaboração de anticorpos pelas células $B$, participação do complemento e a ação de células natural killer ${ }^{14}$.

O perfil da resposta imunitária em ambas as doenças torna provável, portanto, que a infecção pelo vírus da hepatite $B$ tenha sua história natural alterada em pacientes portadores de LV e vice-versa. Parece, porém, não estar estabelecido quais seriam as modificações clínicas, morfológicas, patogenéticas e evolutivas introduzidas por esta co-infecção no quadro isolado de cada doença.

É descrito caso de paciente portador de LV e coinfecção pelo vírus B da hepatite, cuja evolução teve curso fulminante.

\footnotetext{
1. Faculdade de Medicina da Universidade Federal de Minas Gerais, Belo Horizonte, MG

Endereço para correspondência: Prof. Pérsio Godoy. Depto. de Anatomia Patológica e Medicina Legal/FM/UFMG, Av. Prof. Alfredo Balena 190/5 andar, 30130-100 Belo Horizonte, MG.

Recebido para publicação em 22/10/2001.
} 


\section{RELATO DO CASO}

Paciente do sexo masculino, 20 anos, melanoderma, natural e residente em Belo Horizonte, MG. Admitido no Hospital das Clínicas (HC) da Faculdade de Medicina da UFMG com epigastralgia, emagrecimento, icterícia, sonolência, confusão mental e vômitos escuros com sangue.Tabagista e etilista social. Familiares negaram DSTs, promiscuidade ou homossexualismo.

Há dois meses internou-se em outro hospital, com anemia, cefaléia, febre e hepatoesplenomegalia, com cerca de 30 dias de evolução, e os seguintes exames: $\mathrm{Hm}: 2,43 \times 10^{6} / \mathrm{mm}^{3}$, Hb: 5,8g/dl, Ht: 18\%, LG: $1.300 / \mathrm{mm}^{3}$ (granulócitos: $72 \%$, linfócitos: $26 \%$, monócitos: 2\%), plaquetas: $64.000 / \mathrm{mm}^{3}$; albumina: $2,7 \mathrm{~g} / \mathrm{dl}$, globulinas: 3,4g/dl (relação A/G: 0,8); bilirrubina total: $0,6 \mathrm{mg} / \mathrm{dl}$ (bilirrubina direta: 0,2mg/dl), TGO: 124U/l, TGP: 49U/l, FA:471 U/l, atividade de protrombina $65 \%$, RNI: 1,31 ; amilase: 116U/l; VHS: 95(1h), proteína C reativa: 19,2, VDRL não reator; exame parasitológico de fezes e hemoculturas (3 amostras cada) negativos. Radiografia de tórax sem alterações; ultra-som abdominal demonstrou hepatoesplenomegalia. Feita hipótese diagnóstica de provável hiperesplenismo, recebeu antibióticos e hemotransfusões (1000ml de sangue total), seguindo-se alta hospitalar após uma semana.

Ao exame clínico, à admissão no HC (cerca de 90 dias após o início dos primeiros sintomas), o paciente mostrou-se confuso, sonolento, ictérico (2+/4+). PA: $95 \times 60 \mathrm{mmHg}, \mathrm{FC}=\mathrm{FP}: 108 \mathrm{bpm}$, FR: 20irpm. Baço a $10 \mathrm{~cm}$ do rebordo costal esquerdo e fígado a $2 \mathrm{~cm}$ do rebordo costal direito e $3 \mathrm{~cm}$ do apêndice xifóide. Exames laboratoriais: $\mathrm{Hb}$ : $12,8 \mathrm{~g} / \mathrm{dl}, \mathrm{Ht}$ : $42 \%, \mathrm{Hm}$ : 4,9X10\%/ $\mathrm{mm}^{3}$, LG: $5.800 / \mathrm{mm}^{3}$ (granulócitos: $40 \%$, linfócitos: $44 \%$, monócitos: $16 \%$ ), plaquetas: $100.000 /$ $\mathrm{mm}^{3}$; albumina: $2,9 \mathrm{~g} / \mathrm{dl}$, globulinas: $4,6 \mathrm{~g} / \mathrm{dl}$, bilirrubina total: $8,6 \mathrm{mg} / \mathrm{dl}$ (direta: 6,0mg/dl), TGO: $2.885 \mathrm{U} / \mathrm{l}$, TGP: 1.385U/l, FA: 422U/l; glicemia: 40mg/dl, uréia: $22 \mathrm{mg} / \mathrm{dl}$, creatinina $0,7 \mathrm{mg} / \mathrm{dl}$; tempo de protrombina (TP): sangue incoagulável (controle 12seg.), RNI: 4,91 e PTTa: $>120$ seg. (controle: $26 \mathrm{seg}$ ). Estabelecida a hipótese de insuficiência hepática aguda com encefalopatia.

No $2^{\circ}$ dia de internação (DI), não respondia aos comandos verbais nem movimentava ativamente os membros; apresentava abertura ocular espontânea (pupilas $2+/ 2+$ ). Posteriormente, evoluiu com midríase bilateral, pupilas fotorreativas, nistagmo vertical lento, abertura ocular ausente e resposta a estímulo doloroso em descerebração à direita e decorticação à esquerda, além de padrão respiratório irregular (Cheyne-Stokes). LG: $2.200 / \mathrm{mm}^{3}$, plaquetas: $105.000 / \mathrm{mm}^{3}$.

No $3^{\circ} \mathrm{DI}$, respondia ao estímulo doloroso com hiperventilação. Gasometria arterial: $\mathrm{pH}: 7,5, \mathrm{pO}_{2}$ :
95,1 $\mathrm{mmHg}, \mathrm{pCO}_{2}: 20,3 \mathrm{mmHg}$, bicarbonato: 15,8mmol/l, BE: -5,6. Iniciou-se ventilação mecânica. Leucograma com os seguintes resultados: LG: $1.500 / \mathrm{mm}^{3}$ (granulócitos: 30\%, linfócitos: 55\%, monócitos: 15\%), plaquetas: $100.000 / \mathrm{mm}^{3}$; TP: >140seg. (controle: 12,5seg.) e PTTa: $577 \mathrm{seg}$. (controle: $25 \mathrm{seg}$.). Evoluiu em oligúria, taquicardia e febre $\left(38,1^{\circ} \mathrm{C}\right)$; PA: $110 / 60 /$ $20 \mathrm{mmHg}$. Taquiarritmia (FC: 200bpm), pulsos com amplitude reduzida; ECG: taquicardia paroxística supraventricular. Ocorreram, ainda, duas crises convulsivas tônico-clônicas generalizadas.

No $4^{\circ} \mathrm{DI}$, apresentou hipotensão arterial, sem resposta a aminas vasopressoras, anúria, nova crise convulsiva e coma profundo. Gasometria arterial: $\mathrm{pH}$ : 6,98, $\mathrm{pO}_{2}: 169 \mathrm{mmHg}, \mathrm{pCO}_{2}: 16,1 \mathrm{mmHg}$, bicarbonato: 3,6mmol/l, BE: -26,5. Uréia: $15 \mathrm{mg} / \mathrm{dl}$, creatinina: $1,8 \mathrm{mg} /$ dl, TP: infinito, PTTa: >145seg.

Evoluiu para óbito no $5^{\circ} \mathrm{DI}$. Resultados posteriores: HBsAg e anti-HBc-IgM positivos, anti-HCV negativo (anti-HDV e anti-HIV não foram realizados).

Necrópsia (A22080): Leishmaniose visceral grave (Leishmania $s p$; imunohistoquímica fortemente positiva). Infestação maciça do fígado com inumeráveis ninhos de amastigotas nas células de Kupffer, hipertrofiadas e hiperplasiadas, e em hepatócitos isolados (Figura 1); acentuado infiltrado inflamatório linfoplasmocitário difuso, congestão e evidências de mielo e megacariocitopoese (peso do órgão: 1320g); parasitismo e intensa proliferação histiocitária no baço (peso: 980g) e medula óssea; hipoplasia discreta da série granulocítica, com predomínio de células jovens e hipoplasia megacariocítica intensa, plasmocitose discreta. Pneumonia intersticial, representada por infiltrado inflamatório mononuclear e histiócitos com ninhos de leishmanias.

Necrose hepática maciça compatível com hepatite fulminante (sorologia positiva para $\mathrm{HbsAg}$ e anti-HBc IgM) (Figura 2). Congestão e hemorragia pulmonar multifocal (peso do pulmão direito: $500 \mathrm{~g}$; do esquerdo: $350 \mathrm{~g})$. Hidrotórax bilateral $(150 \mathrm{ml}$ à direita e $100 \mathrm{ml}$ à esquerda de líquido amarelo citrino); hidroperitônio $(300 \mathrm{ml})$. Hemorragias focais no peritônio, pleuras e pericárdio.

Encefalopatia hipóxico-isquêmica: necrose neuronal seletiva, relativamente difusa no cortex cerebral, núcleos da base e porção central do tálamo. Alterações astrocitárias compatíveis com encefalopatia hepática. Mielinose pontina central. Edema cerebral discreto e hemorragia intradural parassagital .

\section{DISCUSSÃO}

O caso descrito demonstra co-infecção por Leishmania sp e vírus B da hepatite. Ocorreu hiperinfestação pela Leishmania e grave hepatite. $O$ quadro clínico pareceu resultar da associação das lesões pelos dois agentes, com possibilidade de interação e/ou modificação da resposta imunitária a ambos. 


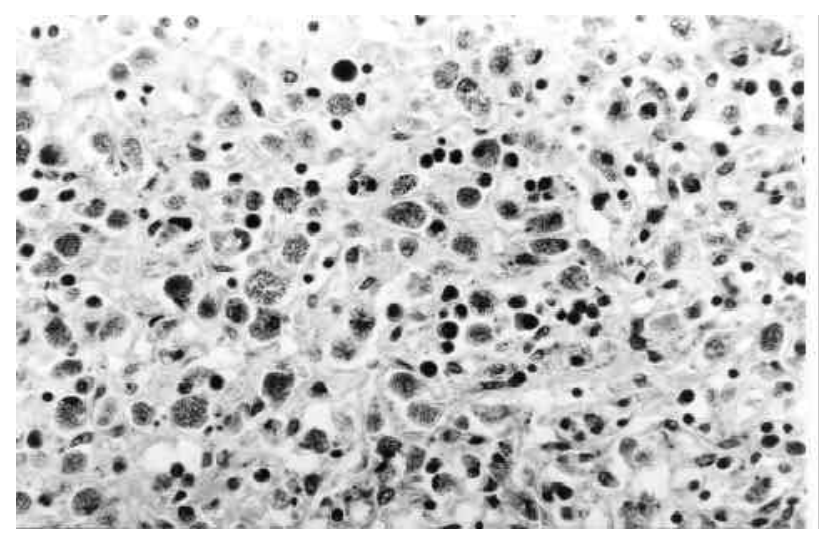

Figura 1- Numerosas células de Küpffer e macrófagos com ninhos de amastigotas (Leishmania sp). HE 640X.

As manifestações hepáticas não representam as mais importantes na leishmaniose visceral, predominando o declínio acentuado do estado geral, febre, esplenomegalia, pancitopenia e hiperglobulinemia; todavia, são descritos casos com acometimento hepático mais grave ${ }^{12}$. Há dois meses, aquele era o quadro clínico do paciente, porém à admissão havia grave insuficiência hepática e acentuada icterícia, transaminases muito elevadas, tempo de protrombina infinito e hiperbilirrubinemia.

A LV à necropsia apresentou no fígado o padrão clássico ${ }^{279}$, salientando-se a hiperplasia e hipertrofia das células de Kupffer intensamente parasitadas; os amastigotas foram observados, também, em macrófagos nos espaços porto-biliares e, mais raramente, em hepatócitos remanescentes, fato considerado incomum, pelo menos à microscopia óptica ${ }^{8}$. Corresponde, possivelmente à infecção pelo vírus $\mathrm{B}$ a necrose hepatocitária maciça e o colapso da trama reticulínica intralobular 6 . A infestação maciça encontrada na medula óssea é comparável ao descrito em pacientes HIVpositivos, quando atinge $100 \%$ dos $\operatorname{casos}^{1316}$.

No caso em questão existem duas hipóteses para o aparecimento da hepatite B: 1) hepatite póstransfusional ou 2) reativação de uma infecção prévia. Considerando a história clínica do paciente, parece mais provável a primeira. O período de incubação da doença correspondeu, aproximadamente, ao observado nos casos de hepatite $B$ (média de 30 a 180 dias), cerca de 70 dias no caso, após a transfusão. Além disso, um dos fatores que influência a gravidade da doença é a carga viral contraída, pois estudos experimentais demonstraram que quanto maior a carga, mais curto

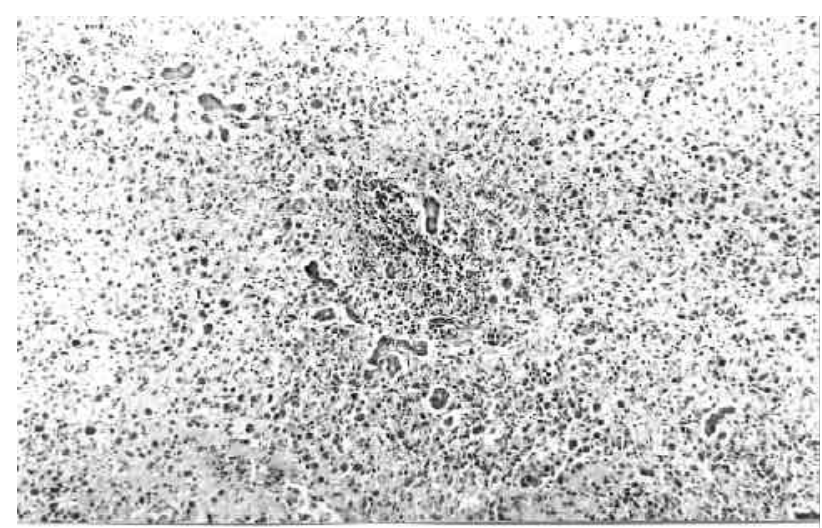

Figura 2 - Necrose hepatocitária grave, infiltrado inflamatório linfoplasmocitário e neocolangiolos: incontáveis células parasitadas por Leishmania sp. (HE 150X).

é o período de incubação e mais provável o desenvolvimento de hepatite ictérica grave, fato que parece comum em transfusões de sangue infectado. A positividade para anti-HBc-IgM, presente no caso, é importante, pois ocorre mesmo nos casos de hepatite fulminante com HbsAg negativo ${ }^{6}{ }^{19}$.

Quando da co-infecção entre a LV e a hepatite pelo vírus $\mathrm{B}$, vários dos mecanismos envolvidos nas doenças isoladamente poderão estar modificados. O sistema interferon está bloqueado na LV e parece essencial em muitas fases do ciclo vital dos vírus da hepatite; o bloqueio das células de Kupffer pela parasitose impediria a elaboração de citocinas, tal como TNF-a, que tem ação bem definida sobre a replicação e transcrição viral ${ }^{14}$. Além disso, a imunidade celular constitui o principal elemento na limitação da disseminação viral. É essencial a função das células T CD4+ e CD8+, resultante da interação específica do receptor celular com um complexo composto de proteína viral (processada) e uma molécula da classe HLA I (CD8+ ou CD4+). A célula T CD4+/HLA II, em geral, reconhece fragmentos de proteínas resultantes da endocitose de antígenos solúveis por células apresentadoras de antígeno. Na hepatite viral essas são representadas provavelmente pelas células de Küpffer, que no caso estão comprometidas pela LV, muito embora as células $B$ circulantes possam exercer este papel (os hepatócitos não expressam as moléculas HLA II) ${ }^{1416}$. Finalmente, as células T citotóxicas que poderiam estar destinadas a participar da defesa contra a leishmaniose seriam desviadas para o combate ao vírus $\mathrm{B}$, o que facilitaria uma superinfecção.

\section{REFERÊNCIAS BIBLIOGRÁFICAS}

1. Alvar J, Cañavate $C$, Gutiérrez-Solar B, Jiménez $M$, Laguna $F$, López-Vélez, R, Molina R, Moreno J. Leishmania and human immunodeficiency virus coinfection: the first 10 years. Clinical Microbiology Reviews 10:298-319, 1997.

2. Bogliolo L. Sobre a anatomia patológica da leishmaniose visceral (a Leishmania donovani). O Hospital 20:591-610, 1941.
3. Campino L, Santos-Gomes GM, Pratlong F, Antunes F, Mauricio I, Dedet JP, Abranches P. HIV / Leishmania co-infections in Portugal: diagnosis and isoenzyme characterization of Leishmania. Annals of Tropical Medicine and Parasitology 91:433-436, 1997. 
4. Carvalho EM, Bacellar O, Barral A, Badaró R, Johnson Jr WD. Antigen-specific immunosuppression in visceral leishmaniasis is cell mediated. Journal of Clinical Investigation 83:860-864, 1989.

5. Carvalho EM, Badaró R, Reed SG, Jones TC, Johnson Jr. WD. Absence of gamma interferon and interleukin-2 production during active visceral leishmaniasis. Journal of Clinical Investigation 76:2066-2069, 1985.

6. Chisari FV, Ferrari C. Hepatitis B virus immunopathogenesis. Annual Reviews of Immunology 13:29-60, 1995.

7. Duarte MIS, Corbett CEP. Histopathological patterns of the liver involvement in visceral leishmaniasis. Revista do Instituto de Medicina Tropical de São Paulo 29:131-136, 1987.

8. Duarte MIS, Mariano ON, Corbett CEP. Liver parenchymal cell parasitism in human visceral leishmaniasis. Virchows Archiv A Pathological Anatomy and Histopathology 415:1-6, 1989.

9. EI Hag IA, Hashim FA, EI Toum IA, Homeida M, El Kalifa M, EI Hassan AM. Liver morphology and function in visceral leishmaniasis (Kala-azar). Journal of Clinical Pathology 47:547-551, 1994.

10. Fattovich G, Giustina G, Adami F. Visceral leishmaniasis complicating chronic hepatitis $B$ treated with interferon. Infection 20:293-294, 1992.

11. Herwaldt BL. Leishmaniasis. Lancet 354:1191-1199, 1999.

12. Khaldi F, Bennaceur B, Ben Othman H, Achouri E, Ayachi R, Regaieg R. Les formes sévères dátteint hépatique au cours de la leishmaniose viscérale: a propos de 7 cas. Archives Française de Pediatric 47: 257-260, 1990.

13. Kemp M. Regulator end effector functions of T-cell subsets in human Leishmania infections. Acta Pathologica, Microbiologica et Immunologica Scandinavica 105 (supl.68):5-33, 1997.

14. Koziel MJ. Immunology of viral hepatitis. The American Journal of Medicine 100:98-109, 1996.

15. Locksley RM, Louis JA. Immunology of leishmaniasis. Current Opinion in Immunology 4:413-418, 1992.

16. Medrano FJ, Rey C, Leal M, Cañabate C, Rubio A, SanchezQuijano A, Alvar J, Lissen E. Dynamics of serum cytokines in patients with visceral leishmaniasis and HIV-1 co-infection. Clinical and Experimental Immunology 114:403-407, 1998.

17. Peters BS, Fish D, Golden R, Evans DA, Bryceson ADM, Pinching AJ. Visceral leishmaniasis in HIV infection and AIDS: clinical features and response to therapy. Quarterly Journal of Medicine, New Series 77:1101-1111, 1990.

18. Sacks DL, Lal SL, Shrivastava SN, Blackwell J, Neva FA. An analysis of $T$ cell responsiveness in Indian Kala-azar. The Journal of Immunology 138:908-913, 1987.

19. Shimizu M, Ohyama M, Takahashi Y, Udo K, Kojima M, Kametani M, Tsuda F, Takai, E, Miyakawa Y, Mayumi M. Immunoglobulin M antibody against hepatitis $B$ core antigen for the diagnosis of fulminant type B hepatitis. Gastroenterology 84:604-610, 1983. 